\title{
From clinical educators to educational scholars and leaders: \\ Strategies for developing and advancing a career in health professions education
}

Subha Ramani ${ }^{1}$, Judy McKimm², Harish Thampy ${ }^{3}$, Patricia S. O’Sullivan ${ }^{4}$ Gary D. Rogers ${ }^{5}$,

Teri Lee Turner ${ }^{6}$, Margaret S. Chisolm ${ }^{7}$, Rashmi A. Kusurkar ${ }^{8}$, Richard Hays ${ }^{9}$, Alice Fornari ${ }^{10}$,

Elizabeth K. Kachur ${ }^{11}$, Keith W. Wilson ${ }^{12}$, Helena P. Filipe ${ }^{13}$, Daniel J. Schumacher ${ }^{14}$

${ }^{1}$ Harvard Medical School, USA, ${ }^{2}$ Swansea University Medical School, UK, ${ }^{3}$ University of

Manchester, UK, ${ }^{4}$ University of California San Francisco, USA, ${ }^{5}$ Griffith University School of Medicine, Australia, ${ }^{6}$ Baylor College of Medicine, USA, ${ }^{7}$ Johns Hopkins University School of

Medicine, USA, ${ }^{8}$ Faculty of Medicine Vrije University Amsterdam, the Netherlands, ${ }^{9}$ James

Cook University, Australia, ${ }^{10}$ Donald and Barbara Zucker SOM at Hofstra/Northwell, USA, 11

Medical Education Development, Global Consulting, New York, USA, ${ }^{12}$ Dalhousie University, Canada, ${ }^{13}$ University of Lisbon, Portugal, ${ }^{14}$ University of Cincinnati College of Medicine, USA.

Corresponding author:

Dr. Subha Ramani

Associate Professor of Medicine, Harvard Medical School

Department of Medicine, Brigham and Women's Hospital

75, Francis Street

Boston, MA 02115, USA

Email: sramani@bwh.harvard.edu

Phone: +1-617-525-7504 


\section{Introduction}

Healthcare practitioners with a passion for education have a range of options to advance their professional trajectory. Health professions education (HPE) is gaining visibility as a specialised field of practice and scholarship. However, just as health professions educator roles vary in scope, responsibilities and nomenclature (Table 1$)^{1-4}$; so do the criteria for academic progression and their interpretation by different promotion committees. Consequently, aspiring educators may find it challenging to prioritise areas of interest, identify activities to achieve personal and institutional goals, and grasp opportunities to develop into academic scholars and leaders, should they wish to do so.

Table 1 here

This toolbox article provides ideas and recommendations for academic and clinical educators seeking roles as educational scholars and leaders. The recommendations, listed under four categories (Figure 1), are based on literature and experts' ideas generated at the 2019 AMEE (Association for Medical Education in Europe) conference. AMEE, an international association for health professions educators, implemented a mentoring programme (comprising one-to-one mentoring meetings and a speed mentoring workshop) in 2019 to encourage networking, collaborations and career development discussions. The mentors were 15 international educational leaders from higher-income countries, and we acknowledge that involving educators from low-resource countries would have brought alternative perspectives.

Figure 1 here

\section{Begin a career as a scholar in health professions education}

Not every educator wants to pursue scholarship and leadership, however, for novice educators who wish to engage in scholarship, strategies that can help to get started include 
identifying areas of interest, joining a team of researchers and scholars, recognising whether your work is adequately original, and completing that first presentation or paper. This can feel overwhelming, but perseverance, mentorship and learning from initial failures can guide successful scholarship. ${ }^{4,5}$ To raise awareness of educational developments, we suggest reading literature on topics of interest, subscribing to email alerts from journals, joining professional associations or online communities and reflecting on potential areas for inquiry in one's educational setting. This helps to identify gaps needing to be addressed in undergraduate, postgraduate and continuing professional development education. Whilst it is tempting to pursue multiple ideas, finding a niche of interest (e.g. assessment, professional identity formation, simulation) can accelerate development of expertise. If you are keen to develop yourself further as an educator or researcher, then formal learning can be invaluable. This will equip you with the jargon, theories and concepts (as well as practical strategies) used in HPE. It is useful to learn how to work with a librarian or use an online repository to run literature searches to stay updated in your area of interest. ${ }^{4}$

If you are interested in research, a mentor can help you identify relevant theoretical and conceptual frameworks, develop research questions and select appropriate methodology. ${ }^{6}$ Good mentors, who are both strong educators and proficient researchers, may be hard to find. Consider establishing a developmental network of supporters and mentors with different but complementary areas of expertise to guide you in conducting rigorous research in areas that interest you. ${ }^{7}$ Try to envision a series of studies to reflect on how outcomes of one study could generate subsequent investigations. Collaborating with a mentor in their research can help ongoing development of skills. For example, journals require ethical approval for most projects 
before considering publication, therefore writing study protocols and applications to Ethics Committees or Institutional Review Boards would be part of the learning.

When initially entering the field of educational research, say “yes” to some projects that may not be completely aligned with your chosen focus. This can create opportunities to establish collaborative relationships and clarify your interests. Scholarship often means volunteering time outside of working hours; this can be difficult to balance with personal and/or professional commitments. Your first funded opportunity may not present itself in your first or second year as an educator. Identify areas of interest, undergo additional training and seek advice from your mentors frequently. While beginning a career as an educational scholar can take many forms, each educator should decide what is feasible for them to pursue based on their workload, personal obligations and career goals.

\section{Continue to advance as mid-career educational scholars}

After joining a community of educational scholars by reading the literature, attending meetings and presenting and/or publishing your work, think about consolidating your scholarly interests. Seek to move from the periphery towards the centre of a scholarly community and sustain the momentum of scholarly outputs. If you are an educator with both clinical and educational obligations, try to make your educational work count twice, i.e. try to publish the educational resources you are designing ${ }^{8}$ and thus align your occupation (what you are paid to do) with your professional vocation (how you want to make an impact). Scholarship is not just original research. In 1990, Ernest Boyer categorised scholarship under four domains: the scholarship of discovery, the scholarship of integration, the scholarship of application, and the scholarship of teaching. ${ }^{9}$ Charles Glassick's standards, summarised in Table 2, can further guide educators in advancement as scholars. 
Table 2 here

Try to familiarise yourself with your institution's educational promotion criteria (serve on the committee if possible) and be strategic about your choice of scholarship/academic activities, document your activities and gather evidence of their impact. Many institutions require staff to maintain a teaching portfolio, an example can be found at:

https://www.mededportal.org/publication/626/. Mentors and colleagues can provide advice on career development and feedback on your CV and educational portfolio. Many educators are generous with their time and advice; do not hesitate to reach out to scholars and leaders you already know and email people you don't know for guidance. Attending and volunteering at educational meetings, facilitating workshops with educators outside your institution and engaging in social media can help you to connect with national and international collaborators and organisations. Opportunities to network include arriving early at workshops, sitting next to someone you do not know and exploring common interests and projects. Consider preparing an ‘elevator pitch’, a persuasive summary of your work and expertise that can be described succinctly. ${ }^{10}$ Alongside developing links outside your institution, keep your own educational leaders or supervisors updated on your work and consider seeking external professional recognition e.g. as an AMEE or Advance HE Fellow.

\section{Seek leadership roles in health professions education}

Leadership requires a unique set of skills, a sense of organisational mission, and understanding the context and systems within which you work. ${ }^{3}$ Moving to an educational leadership role from a clinical one requires an identity shift and a reappraisal of your own strengths and weaknesses. A 5-year plan that includes positions or qualifications you would like 
to achieve, your educational philosophy and vision and how to pursue it can make it easier for you to decide which initiatives and projects to engage in and which ones to defer.

Effective leadership involves studying the body of literature on education and leadership, management, followership (highly effective team members who work closely with leaders and actively contribute towards accomplishment of defined goals) and willingness to discover and apply new ideas. ${ }^{3}$ Effective leaders are also skilled at creating a psychologically safe environment, relationship-building and respecting and inviting suggestions from the whole team. Professional development activities can help develop specific skills in: academic leadership, change management, leading meetings, delegation and empowerment, negotiation, public speaking, financial management, planning and project management, and emotional intelligence. $^{11}$

Volunteer or solicit nominations to serve on local and national education committees and task forces. We recommend getting involved with local and regional societies, networking with regional leaders and slowly expanding your horizon to national and international society committees. Be willing to take on small leadership roles, such as managing small projects or developing and implementing a focussed assessment method. Enthusiasm, meeting deadlines, and willingness to take on tasks including those at the margins of your comfort zone can help others to recognise your leadership potential and think about you for future opportunities.

Observing coaches, mentors, colleagues and friends in their leadership roles can be a rich experience. Ask them as well as near peers to give you honest, constructive feedback on how you impact others, your strengths and areas for development, and how you can cultivate your leadership style. Maintaining an effective relationship with your supervisors (managing up) and keeping them informed about your successes and challenges are important even when one is near 
the top of any hierarchy. You may be regarded as a sound candidate for larger leadership positions if you demonstrate problem solving skills and help deliver better outcomes.

When working relationships need to be terminated, it is important to do so without conflict. Career development continues even after taking on leadership roles and you may find yourself working alongside or reporting to colleagues you once managed or with whom you had a prior working relationship.

\section{Engage in reflective practice as a health professions educator}

At all career stages, self-awareness, a positive mindset and reflective practice are critical for growth. Reflective practice includes the ability to reflect in (during an activity resulting in immediate change in action), on (after an activity for future change in action plans) and for (towards goals for personal, professional and institutional growth) action. ${ }^{12}$

Curiosity, collaboration, authenticity, creativity, consistency, humility and ability to align own values with that of the institution are essential qualities for reflective practice. These characteristics pave the way for meaningful and sustainable change at the organisational/institutional level and are part of being an effective scholar and leader. Other important qualities include the ability to inspire and mentor others, , willingness to collaborate with peers, juniors and seniors, and acknowledgement of their expertise and experience.

Experienced scholars and leaders continually seek out activities to explore a new area of practice and develop new skills. Such activities can build a peer-mentoring group outside your own organisation. For the mid- to late-career faculty member, self-curation through selection of conference presentations, audiobooks, webinars, workshops, podcasts, and literature reading is an appropriate means for staying current and discovering new ideas. This requires staying open and curious, rather than merely reinforcing existing beliefs that could become prejudices. 
Whenever feasible, engage in a community of practice (CoP) (a group with shared interests, passion and commitment who learn from each other) for professional development. ${ }^{13}$ As a novice educator, you may start at the periphery of a CoP, however, as you advance in your career, you engage more with the community and move closer to the centre. As a leader, nurture development of CoPs, ideally anchored in common values and shared commitments and resources, welcome new members into the community, and allow everyone to contribute to ongoing learning and growth within the community.

Appreciative inquiry is ahelpful framework for program development and implementation. ${ }^{14}$ In contrast to a focus on problem solving, appreciative inquiry engages in self-determined change by identifying the positive outcomes and envisioning what might work well in the future rather than trying to fix what is broken. Finally, work on mentorship skill development to maximise benefits to the mentee and mentor. ${ }^{15}$ You do not automatically develop these capabilities just by seniority and it requires a collaborative humanistic approach to professional development.

\section{Conclusion}

This toolbox article focusses on helping academic clinical professionals to become successful educational scholars and leaders. For those entering the field, finding their passion, trying out new things, networking and seeking a team of mentors will be highly rewarding. For mid-career educators, developing a niche, consolidating areas of interest, gaining expertise in targeted areas, sustaining scholarship and mentoring others can promote continued development. Those who take on educational leadership roles should develop their leadership skills, volunteer to take on committee and other roles nationally and internationally, seek multisource feedback, thus 
positioning themselves as excellent candidates for larger leadership and mentoring roles.

Reflective practice, curiosity, humility and authenticity are characteristics essential for educational scholars and leaders at all levels. The suggestions in this article provide a menu of options and clinical educators should select what is feasible and applicable to their own context and professional goals. After all, even the most successful educational scholars and leaders will thoughtfully consider which balls to juggle. 


\section{Acknowledgements}

We gratefully acknowledge Professor David Irby for his contributions on the leadership team of the AMEE mentoring initiative, as a mentor and workshop leader, as well as his valuable and generous advice to the authorship team. 


\section{References}

1. Geraci SA, Babbott SF, Hollander H, et al. AAIM Report on Master Teachers and Clinician Educators Part 1: needs and skills. Am J Med. 2010;123(8):769-773.

2. Sherbino J, Frank JR, Snell L. Defining the key roles and competencies of the clinicianeducator of the 21st century: a national mixed-methods study. Acad Med. 2014;89(5):783-789.

3. McKimm J, O'Sullivan H. When I say ... leadership. Med Educ. 2016;50(9):896-897.

4. McGaghie WC. Scholarship, publication, and career advancement in health professions education: AMEE Guide No. 43. Med Teach. 2009;31(7):574-590.

5. Wang FY, Stankiewicz CA, Bennett NL, Myers JS. Hit the Ground Running: Engaging Early-Career Medical Educators in Scholarly Activity. Acad Med. 2019;94(11):1837.

6. Bordage G, Lineberry M, Yudkowsky R. Conceptual Frameworks to Guide Research and Development (R\&D) in Health Professions Education. Acad Med. 2016;91(12):e2.

7. DeCastro R, Sambuco D, Ubel PA, Stewart A, Jagsi R. Mentor networks in academic medicine: moving beyond a dyadic conception of mentoring for junior faculty researchers. Acad Med. 2013;88(4):488-496.

8. Simpson D, Fincher RM, Hafler JP, et al. Advancing educators and education by defining the components and evidence associated with educational scholarship. Med Educ. 2007;41(10):1002-1009.

9. Glassick CE. Boyer's expanded definitions of scholarship, the standards for assessing scholarship, and the elusiveness of the scholarship of teaching. Acad Med. 2000;75(9):877-880. 
10. Dzara K, Kesselheim J. Going Up? Tips for the Medical Educator's "Elevator Pitch". Acad Med. 2018;93(12):1884.

11. Swanwick T, McKimm J. Faculty development for leadership and management. . In: Steinert Y, ed. Faculty development in the health professions: a focus on research and practice. Dordrecht ; New York: Springer; 2014:53-78.

12. Schön DA. Educating the reflective practitioner : toward a new design for teaching and learning in the professions. 1st ed. San Francisco: Jossey-Bass; 1987.

13. de Carvalho-Filho MA, Tio RA, Steinert Y. Twelve tips for implementing a community of practice for faculty development. Med Teach. Feb 1 2019, published online.

14. Sandars J, Murdoch-Eaton D. Appreciative inquiry in medical education. Med Teach. 2017;39(2):123-127.

15. Ramani S, Gruppen L, Kachur EK. Twelve tips for developing effective mentors. Med Teach. 2006;28(5):404-408. 
Table 1: The spectrum of HPE roles and definitions

\begin{tabular}{|l|l|}
\hline HPE role & Definition \\
\hline Teachers & Actively engage in teaching health professionals and serve critical \\
& $\begin{array}{l}\text { Apply theory and evidence to inform their teaching, design } \\
\text { educational products, engage in scholarly presentations and/or } \\
\text { publications }{ }^{2}\end{array}$ \\
\hline Scholars & $\begin{array}{l}\text { Pose questions about the theoretical basis of teaching and learning, } \\
\text { explore the impact of educational initiatives and disseminate findings } \\
\text { externally }\end{array}$ \\
\hline Leaders & $\begin{array}{l}\text { Lead educational initiatives, programmes or departments of education } \\
\text { and oversee teams of teachers, scholars and educators }\end{array}$ \\
\hline
\end{tabular}


Table 2: Glassick’s standards of excellence in educational scholarship ${ }^{9}$

(1) Clear Goals: Identify important questions in the field, state the purpose of the work clearly, and establish objectives that are realistic and achievable.

(2) Adequate Preparation: Show an understanding of existing scholarship in the field, develop the necessary skills and resources to conduct the project.

(3) Appropriate Methods: Use methods appropriate to the goals, apply them effectively and modify them in response to changing circumstances.

(4) Significant Results: This step refers to achievement of educational goals and not to statistical significance. Goals should be achieved adequately, add to the field and open areas for further exploration.

(5) Effective Presentation: Present work using an effective style, organisation, and with clarity and integrity.

(6) Reflective Critique: Critically evaluate own work, use reflections to improve the quality of future work. 
Figure 1: Four foundations for moving from teaching and education to scholarship and leadership for health professions educators

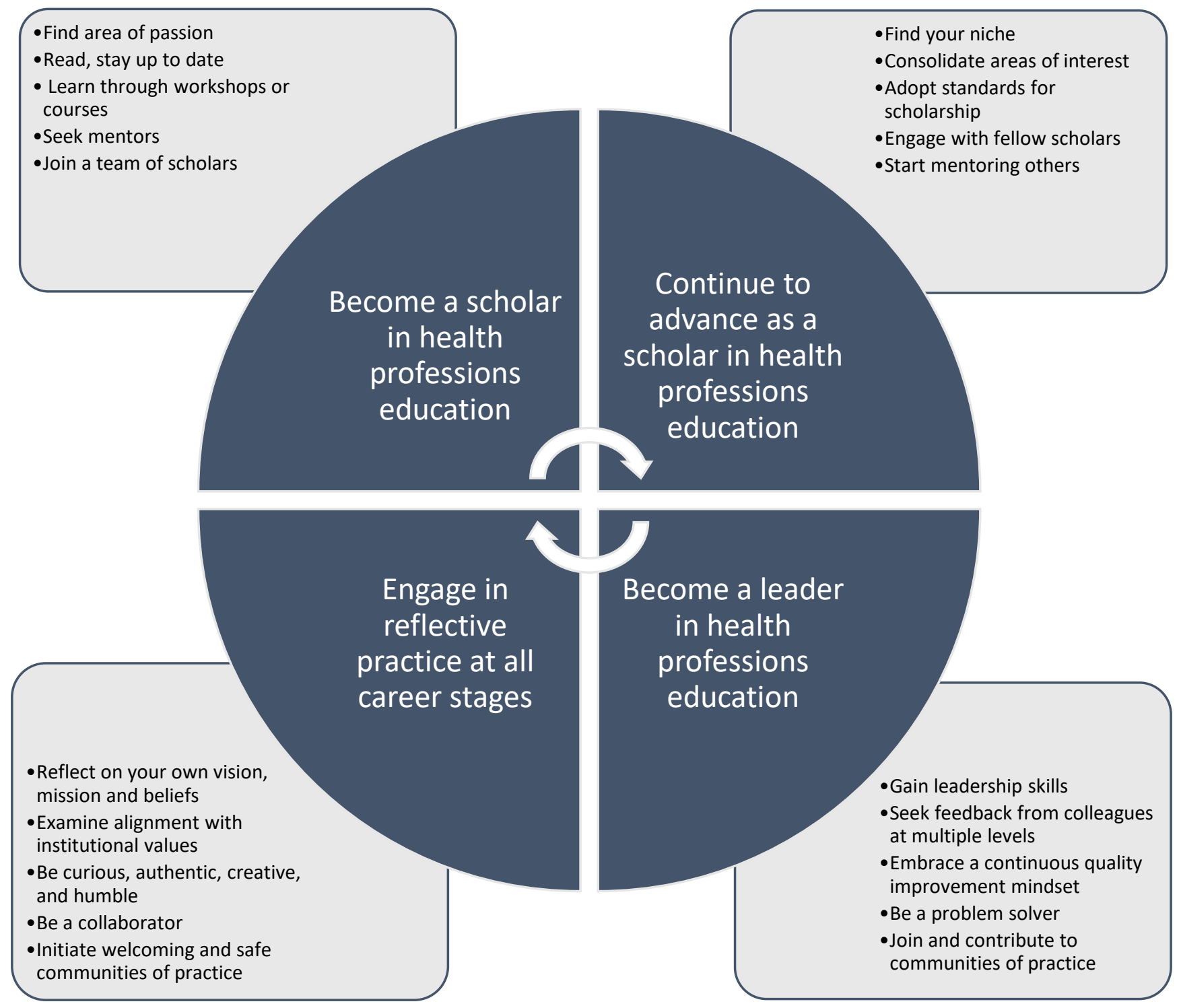

